\title{
Association between a nucleotide polymorphism in the calpain 10 gene and carbohydrate metabolism disturbances in patients with polycystic ovary syndrome
}

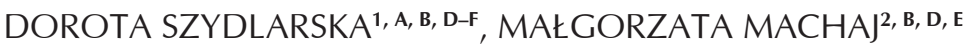

${ }^{1}$ Family Medicine Outpatient Clinic of the Central Clinical Hospital of the Ministry of the Interior and Administration in Warsaw

${ }^{2}$ Department of Organization and Human Resources of the Central Clinical Hospital of the Ministry of the Interior and Administration in Warsaw

A - Study Design, B - Data Collection, C - Statistical Analysis, D - Data Interpretation, E - Manuscript Preparation, $\mathbf{F}$ - Literature Search, $\mathbf{G}$ - Funds Collection

Summary Polycystic ovary syndrome (PCOS) is a heterogeneous disease entity affecting a significant percentage of women of childbearing age. Despite of the prevalence of this endocrinopathy, the pathogenesis of PCOS is still not fully understood. In recent years, the significant role of insulin in the pathogenesis of PCOS has been emphasized. The coexistence of genetic syndromes of insulin resistance and hyperandrogenism, frequent occurrence of glucose tolerance disorders in women with PCOS and efficacy of the treatment, leading to increased sensitivity to insulin in the treatment of symptoms of PCOS, constitute indirect evidence for the participation of insulin in the pathogenesis of PCOS. Insulin resistance may be present in both lean and obese women with PCOS, and thus it is not directly related to body mass. As a result of years of intensive scientific work aimed at identifying the gene, it has been established that in the study population, a relationship between several polymorphisms (SNPs, single nucleotide polymorphisms) of the calpain 10 gene, a representative of a large family of cytoplasmic proteases, and development of carbohydrate metabolism disorders, including diabetes, exists. The risk of developing type 2 diabetes is not associated with a variant of a single polymorphism of the gene, but rather results from the haplotypes created by alleles of three SNPs, which have been numbered 19,43,63. This paper is a summary of recent reports on the presence of the relationship between a single nucleotide polymorphism of the calpain gene and the development of glucose metabolism disturbances in patients with polycystic ovary syndrome. The importance of the calpain 10 gene in the pathogenesis of type 2 diabetes seems vary in different populations and ethnic groups and is likely to be the subject of numerous further studies in the coming years. Key words: diabetes, hyperandrogenism, single nucleotide polymorphism.

Szydlarska D, Machaj M. Association between a nucleotide polymorphism in the calpain 10 gene and carbohydrate metabolism disturbances in patients with polycystic ovary syndrome. Fam Med Prim Care Rev 2016; 18(4): 497-500, doi: 10.5114/ fmpcr.2016.63711.

Polycystic ovary syndrome (PCOS) is a heterogeneous disease entity affecting a significant percentage of women of childbearing age. It is believed that PCOS occurs in approximately $10 \%$ of women of reproductive age. In its classic form, this syndrome was first described by Stein and Leventhal in 1935, who observed the co-occurrence of amenorrhea and accompanying hirsutism, obesity and ovarian enlargement. The definition and diagnostic criteria for PCOS were proposed as late as in 1990 [1]. Diagnostic criteria for PCOS include: absence of ovulation, menstrual disorders of oligo/amenorrhea type and/or biochemical symptoms of hyperandrogenism. An important element of PCOS diagnosis is the exclusion of other clinical syndromes of a similar clinical picture, such as: androgen-secreting tumors, late revealing metabolic blocks of steroidogenesis or hypercortisolism. In 2003, the existing criteria for PCOS diagnosis were modified. The criteria added to the existing criteria included a typical ovarian picture identified by ultrasound examination, determined as: increase in the field and volume of ovaries, increase in the roundness coefficient of the ovary (ovarian width/ ovarian length), the presence of microcysts having dimensions below $10 \mathrm{~mm}$ in a number higher than 11. Despite the prevalence of this endocrinop- athy, the pathogenesis of PCOS still remains questionable and is not fully understood. In recent years, the significant role of insulin in the pathogenesis of PCOS has been emphasized. The coexistence of genetic syndromes of insulin resistance and hyperandrogenism, frequent occurrence of glucose tolerance disorders in women with PCOS and efficacy of the treatment, leading to increased sensitivity to insulin in the treatment of symptoms of PCOS, constitute indirect evidence for the participation of insulin in the PCOS pathogenesis. Furthermore, in patients suffering from PCOS, an increased risk of the occurrence of carbohydrate metabolism disturbances was demonstrated, although the resistance of peripheral tissues to insulin and impaired insulin secretion are also present in women suffering from PCOS without diabetes. It was observed that insulin resistance may be present in both lean and obese women with PCOS, and thus it is not directly related to body mass [1].

In 1996, a relationship between the region in the $2 q$ chromosome and type 2 diabetes in the population of Mexican Americans in Texas was described [2]. As a result of years of intensive scientific work aimed at identifying the gene, it has been established that in the study population, a relationship between several polymorphisms (SNPs, single 
nucleotide polymorphisms) of the calpain 10 gene, a representative of a large family of cytoplasmic proteases, and development of carbohydrate metabolism disorders, including diabetes, exists [3]. The risk of developing type 2 diabetes is not associated with a variant of a single polymorphism of the gene, but rather results from the haplotypes created by alleles of three SNPs, which have been numbered 19, 43, 63. All these SNPs are located in introns, they do not have a direct impact on the amino acid structure of the protein, and their importance at the molecular level still requires further studies. However, there is a high probability that they affect the level of gene expression [3,4]. A possible influence of polymorphisms in the calpain 10 gene on insulin sensitivity is confirmed by the differences in body masses in the groups of carriers of the individual haplotypes [5]. The importance of the calpain 10 gene in the pathogenesis of type 2 diabetes seems to vary in different populations and ethnic groups and is likely to be the subject of numerous further studies in the coming years. In Mexican Americans, this gene appears to be responsible for $14 \%$ of cases of type 2 diabetes, while in the population of the United Kingdom, this percentage is approximately $6 \%[3,6]$. It is interesting that statistical evidence supports the fact that there is a relationship between the calpain 10 gene located on chromosome 2 and a still unidentified gene present on chromosome $15[3,7]$. An indirect confirmation of the pathogenic role of calpain 10 in type 2 diabetes is the fact that during treatment with protease inhibitors, glucose intolerance developed in patients with AIDS [8]. The mechanism of impaired glucose tolerance associated with the calpain 10 gene has not been yet explained. Calpains are a large family of intracellular proteases participating in the decomposition of other proteins; they can also activate and modulate the activity of other enzymes [9]. Calpains have two key domains exhibiting different metabolic functions. The first of these domains has endoproteinase activity, while the second one-calmodulin, having the ability to bind calcium ions. Therefore, the activity of calpains is controlled by intracellular calcium concentration, although there is also evidence of a direct stimulatory effect of 1,25-dihydroxyvitamin $D_{3}$ on their activity [10]. Most of the proteins of the calpain family are expressed in all tissues of the human body, which indicates their importance in maintaining essential cellular functions. There is evidence for the role of these proteins in the pathophysiology of certain diseases in humans. It is believed that their activity affects the extent of necrosis in acute ischemia of the central nervous system. Calpain inhibitors reduce postischemic changes in the brain, which potentially creates the possibility of their use in humans. Calpains were also demonstrated to affect the apoptosis process. It is probably that a high activity of calpains plays a role in the pathogenesis of Alzheimer's disease [9]. To summarize, recent reports on the role of the calpain 10 gene in the pathogenesis of type 2 diabetes constitutes very interesting scientific material. Although numerous questions are still waiting for an answer, it is already possible to say that this is a true scientific breakthrough concerning not only the genetic background and pathogenesis of type 2 diabetes, but also of other diseases of a complex nature. The relationship between the encoding of cysteine in the calpain 10 gene and the occurrence of insulin resistance and type 2 diabetes has been emphasized [11, 12 ]. In PCOS and type 2 diabetes, there are many common etiological factors [13]. The occurrence of the relationship $(p=0.027)$ between SNP43 polymorphism of the calpain 10 gene and the risk of PCOS development in Chilean women has been reported [14]. Similar results were obtained by other researches in a group of women in Brazil [15]. Spanish researchers observed a relationship between the occurrences of PCOS and UCSNP-44, but not UCSNP-43 polymorphism [16]. Similarly, American researchers did not demonstrate a relationship between the occurrence of PCOS and UCSNP-43 [17]. A study of British researchers demonstrated no relationship between PCOS and UCSNP-43 and UCSNP-44 [18]. There is data confirming a relationship between UCSNP-43 and an increased risk of development of type 2 diabetes and metabolic syndrome in diabetes [15, 19]. A relationship between UCSNP-43 and UCSNP-44 and lipid metabolism disorders in women with PCOS without diabetes $[20,21]$ was also reported. Numerous studies demonstrated a relationship between polymorphism of the calpain 10 gene and the occurrence of metabolic disorders in PCOS [22-24]. Tkać et al. evaluated the effect of the calpain gene on the efficacy of treatment in 6-month metformin therapy in a study which involved 148 people with type 2 diabetes [25]. They found that the presence of $G$ allele affects the reduction of glycated hemoglobin less that the presence of A allele. The study of Arslan et al. also confirmed the relationship between the presence of haplotype 121 and 122/121 haplotype of SNP-19,-44 and -63 of the calpain 10 gene and the development of type 2 diabetes in the Turkish population [26]. A study performed on a Kurdish ethnic group originating from the western part of Iran also demonstrated the relationship between SNP-43, but not SNP-19, -63, and the development of type 2 diabetes [27]. The role of polymorphism of the calpain 10 gene was the subject of many scientific discussions. It was demonstrated that the calpain 10 gene is involved in molecular mechanisms which increase the risk of the development of type 2 diabetes [28]. Based on the performed meta-analysis of 11 scientific studies, Huang et al. demonstrated a relationship between a polymorphism of the calpain 10 gene and the development of PCOS [29]. Calpain 10 gene polymorphism may be responsible not only for the development of carbohydrate metabolism disturbances, but also for phenotypic characteristics, such as hirsutism. It is not entirely clear whether calpain 10 polymorphism may affect the development of gestational diabetes [30]. A meta-analysis, which included a total of 623 women with PCOS, demonstrated a relationship between calpain 10 polymorphism and the development of PCOS. The most common haplotype, TGG3AGCA, was associated with a lower risk of PCOS development $(\mathrm{OR}=0.487, p=0.0057)$, while the TGA2AGCA haplotype increased the risk of PCOS development $(\mathrm{OR}=$ $3.557, p=0.0011$ ) [31]. The study of Shilpi et al., which involved 250 women with PCOS and 299 women in a control group from the region of southern India, demonstrated that the presence of SNP-56 and SNP-19 was associated with a protective role towards PCOS development [32]. At the same time, a twofold higher incidence of PCOS in SNP-44 and SNP-19 $(p=0.03)$ female carriers was demonstrated.

Analysis of the relationship between gene polymorphism and the risk of PCOS development is still a current issue. The pathogenesis of PCOS, which has not been fully explained, determines the search for new aspects of development of this disease entity. A relationship between polymorphism of the luteinizing hormone receptor and the development of PCOS was demonstrated [33]. In women with TT genotype, higher concentrations of total testosterone, triglycerides and LDL cholesterol were found. No relationship between gene polymorphism in the insulin receptor and the risk of PCOS development was found [34]. A relationship between IL-6 gene polymorphism and the development of PCOS was demonstrated [35]. The study of Radavelli-Bagatini revealed a relationship between adiponectin gene polymorphism and a tendency to hypertension, as well as the development of PCOS, which was confirmed in other studies [36-38]. However, the reports on this subject are contradictory. Other researchers did not demonstrate a relationship between adiponectin gene polymorphism and the development of PCOS, while a relationship between resistin gene polymorphism and PCOS was found [39]. 
In conclusion, it should be stated that PCOS is a disease entity with a wide spectrum of phenotypes and a complex, multi-component etiology, which still leaves many questions and, at the same time, a wide field for scientific activities. In PCOS and type 2 diabetes, there are many common etiological factors. In many studies, researchers have emphasized the existence of a relationship between calpain 10 gene polymorphism and the development of PCOS in many differentiated populations of women. The described disease entity, because of the coexistence of hormonal disorders, infertility, metabolic disorders and sexual dysfunctions, comprises health problems which require an interdisciplinary approach. The group of specialists involved in the diagnostics and treatment of women with PCOS comprises endocrinologists, gynecologists, hypertensiologists and sexologists. Because of the prevalence of PCOS and concomitant metabolic disorders, this also constitutes a challenge in the practice of a family doctor.

Source of funding: This work was funded by the authors' resources.

Conflict of interest: The authors declare no conflict of interests.

\section{References}

1. Szydlarska D, Grzesiuk W, Bar-Andziak E. Kontrowersje wokół patogenezy zespołu policystycznych jajników. Endokrynol Otył Zab Przem Mat 2010; 3(6): 141-146.

2. Hanis $\mathrm{CL}$, Boerwinkle E, Chakraborty R, et al. A genome-wide search for human non-insulin-dependent (type 2) diabetes genes reveals a major susceptibility locus on chromosome 2 . Nat Genet 1996; 13(2): 161-166.

3. Horikawa Y, Oda N, Cox NJ, et al. Genetic variation in the gene encoding calpain-10 is associated with type 2 diabetes mellitus. Nat Genet 2000; 26(2): 163-175.

4. Colilla S, Cox NJ, Ehrmann DA. Heritability of insulin secretion and insulin action in women with polycystic ovary syndrome and their first degree relatives. J Clin Endocrinol Metab 2001; 86(5): 2027-2031.

5. Baier LJ, Permana PA, Yang X, et al. A calpain-10 gene polymorphism is associated with reduced muscle mRNA levels and insulin resistance. J Clin Invest 2000; 106(7): 69-73.

6. Frayling TM, Evans JC, Ellard S, et al. Study group BDA Warren 2 Consortium: Transmission disequilibrium at the calpain10/ /NIDDM1 gene in UK Caucasian type 2 diabetes parent-offspring trios. Diabetes 2000; 49(Suppl. 1): 30.

7. Cox NJ, Frigge M, Nicolae DL, et al. Loci on chromosome 2 (NIDDM1) and 15 interact to increase susceptibility to type 2 diabetes in Mexican Americans. Nat Genet 1999; 21(2): 213-215.

8. Martinez E, Conget I, Lozano L, et al. Reversion of metabolic abnormalities after switching from HIV-1 protease inhibitors to nevirapine. AIDS 1999; 13(7): 805-810.

9. Sorimachi H, Ishiura S, Suzuki K. Structure and physiological function of calpains. Biochem J 1997; 328(3): 721-732.

10. Ravid A, Koren R, Rotem $C$, et al. 1,25-dihydroxyvitamin $D_{3}$ increases the cellular content of the calcium-activated neutral protease mu-calpain in renal cell carcinoma. Endocrinology 1994; 135(6): 2822-2825.

11. Horikawa Y, Oda N, Cox NJ, et al. Genetic variation in the gene encoding calpain-10 is associated with type 2 diabetes mellitus. Nat Genet 2000; 26(2): 163-175.

12. Evans JC, Frayling TM, Cassell PG, et al. Studies of association between the gene for calpain-10 and type 2 diabetes mellitus in the United Kingdom. Am J Hum Genet 2001; 69(3): 544-552.

13. Conn JJ, Jacobs HS, Conway GS. The prevalence of polycystic ovaries in women with type 2 diabetes mellitus. Clin Endocrinol (Oxf) 2000; 52(1): 81-86.

14. Marquez JL, Pacheco A, Valdes P, et al. Association between CAPN10 UCSNP-43 gene polymorphism and polycystic ovary syndrome in Chilean women. Clinica Chimica Acta 2008; 398(1-2): 5-9.

15. Wiltgren D, Furtado L, Kohek MB, et al. CAPN 10 UCSNP-43, UCSNP-19 and UCSNP-63 polymorphism and metabolic syndrome in polycystic ovary syndrome. Gynecol Endocrinol 2007; 23(3): 173-178.

16. Gonzalez A, Abril E, Roca A, et al. Specific CAPN 10 haplotypes influence the clinical profile of polycystic ovary syndrome. J Clin Endocrinol Metab 2003; 88(11): 5529-5536.

17. Ehrman D, Schwarz PE, Hara M, et al. Relationship of calpain-10 genotype to phenotypic features of polycystic ovary syndrome. J Clin Endocrinol Metab 2002; 87(4): 1669-1673.

18. Haddad L, Evans JC, Gharani N, et al. Variation within the type of 2 diabetes susceptibity gene calpain-10 and polycystic ovary syndrome. J Clin Endocrinol Metab 2002; 87(6): 2606-2610.

19. Orho-Melander M, Klannemark M, Svensson MK, et al. Variants in the calpain-10 gene predispose to insulin resistance and elevated free fatty acid levels. Diabetes 2002; 51(8): 2658-2664.

20. Daimon M, Oizumi T, Saitoh T, et al. Calpain 10 gene polymorphism are related, not to type 2 diabetes, but to increased serum cholesterol in Japanese. Diabetes Res Clin Pract 2002; 56(2): 147-152.

21. Carlsson E, Frediksson J, Groop L, et al. Variation in the calpain-10 gene is associated with elevated triglyceride levels and reduced adipose tissue messenger ribonucleic acid expression in obese Swedish subjects. J Clin Endocrinol Metab 2004; 89(7): 3601-3605.

22. Ben SA, Attaoua R, Mtriraoui N, et al. Common polymorphisms of calpain-10 and the risk of polycystic ovary syndrome in Tunisian population: a case-control study. Mol Biol Rep 2014; 41(10): 6569-6574.

23. Flores-Martinez SE, Castro-Martinez AG, Lopez-Quintero A, et al. Association analysis of SNP-63 and indel-19 variant in the calpain-10 gene with polycystic ovary syndrome in women of reproductive age. Cir Cir 2015; 83(1): 35-42.

24. Shen $\mathrm{W}, \mathrm{Li} \mathrm{T}, \mathrm{Hu}$ Y, et al. Calpain-10 genetic polymorphisms and polycystic ovary syndrome risk: a meta-analysis and metaregression. Gene 2013; 531(2): 426-434.

25. Tkac I, Javorsky M, Klimcakova L, et al. A pharmacogenetic association between a variation in calpain 10 (CAPN10) gene and the response to metformin treatment in patients with type 2 diabetes. Eur J Clin Pharmacol 2015; 71(1): 59-63.

26. Arslan E, Acik L, Gunaltili G, et al. The effect of calpain-10 gene polymorphism on the development of type 2 diabetes mellitus in a Turkish population. Endokrynol Pol 2014; 65(2): 90-95.

27. Maleki F, Haghani K, Shokouhi S, et al. A case-control study on the association of common variants of CAPN10 gene and the risk of type 2 diabetes in an Iranian population. Clin Lab 2014; 60(4): 663-670.

28. Panico P, Salazar AM, Burns AL, et al. Role of calpain-10 in the development of diabetes mellitus and its complications. Arch Med Res 2014; 45(2): 103-115. 
29. Huang M, Xiao J, Zhao X, et al. Four polymorphisms of the CAPN 10 gene and their relationship to polycystic ovary syndrome susceptibility: a meta-analysis. Clin Endocrinol (Oxf) 2012; 76(3): 431-438.

30. Issat T, Nowicka MA, Jakimiuk AJ. Zespół policystycznych jajników (PCOS), a ryzyko występowania cukrzycy ciążowej (GDM). Ginekol Pol 2015; 86(5): 392-395.

31. Vollmert C, Hahn S, Lamina C, et al. Calpain-10 variants and haplotypes are associated with polycystic ovary syndrome in Caucasians. Am J Physiol Endocrinol Metab 2007; 292(3): 836-844.

32. Shilpi D, Pisapati VS, Kudugunti N, et al. Association of CAPN10 SNPs and haplotypes with polycystic ovary syndrome among South Indian women. PLoS ONE 2012; 7(2): e32192.

33. Ha L, Shi Y, Zhao J, et al. Association study between polycystic ovarian syndrome and the susceptibility genes polymorphisms in Hui Chinese women. PLoS ONE 2015; 10(5): e0126505.

34. Bagheri M, Abdi-Rad I, Hosseini-Jazani N, et al. An Association study between INSR/Nsil (rs2059806) and INSR/PmlI (rs1799817) SNPs in women with polycystic ovary syndrome from West Azerbaijan Province, Iran. J Reprod Infertil 2015; 16(2): 109-112.

35. Tumu VR, Govatati S, Guruvaiah P, et al. An interleukin-6 gene promoter polymorphism is associated with polycystic ovary syndrome in South Indian women. J Assist Reprod Genet 2013; 30(12): 1541-1546.

36. Radavelli-Bagatini S, de Oliveira IO, Ramos RB, et al. Haplotype TGTG from SNP 45T/G and 276G/T of the adiponectin gene contributes to risk of polycystic ovary syndrome. J Endocrinol Invest 2013; 36(7): 497-502.

37. Zhang W, Wei D, Sun X, et al. Family-based analysis of adiponectin gene polymorphisms in Chinese Han polycystic ovary syndrome. Fertil Steril 2014; 101(5): 1419-1423.

38. Yang $\mathrm{Z}$, Yang $\mathrm{X}, \mathrm{Xu}$ J, et al. Association between adiponectin receptor 1 gene polymorphism and insulin resistance in Chinese patients with polycystic ovary syndrome. Gynecol Obstet Incest 2014; 77(1): 45-49.

39. Baba T, Endo T, Sata F, et al. The contributions of resistin and adiponectin gene single nucleotide polymorphisms to the genetic risk for polycystic ovary syndrome in a Japanese population. Gynecol Endocrinol 2009; 25(8): 498-503.

Tables: 0

Figures: 0

References: 39

Received: 26.10 .2015

Revised: 12.01.2016

Accepted: 12.01.2016

Address for correspondence:

Dorota Szydlarska, MD, PhD

Przychodnia MSWiA

ul. Wołoska 137

02-507 Warszawa

Polska

Tel.: + 4822 508-15-50

E-mail: dorota.szydlarska@cskmswia.pl 